\title{
SIMULATION OF MEDIA MOVEMENT PROCESS IN THE REGULAR ANGLED HEAD WITH A BAFFLE
}

\author{
• • йруллин, • • узнецов
}

A. F. Khairullin, V. A. Kuznetsov

шкирский госуд рственный университет, г. $\phi$

лючевые слов : моделиров ние; регулярн я уголков ян с дк;м ссообмен; гидродин мик Key words: simulation; regular angled head with; mass-transfer; hydrodynamics

ссообменные устройств с отбойными элемент ми [1] н шли широкое применение в процесс х перер ботки нефти. обл сти нефтеперер ботки в жную роль игр ют колонные пп р ты, осн щенные конт ктными устройств ми, в которых н блюд ется низкое гидр влическое сопротивление и повышенн я устойчивость к з бивке з грязнениями. дн ко д нных по моделиров нию процесс движения сред в регулярных уголковых н с дк х в технической литер туре недост точно [2, 3].

ыли проведены исследов ния по гидр влическому сопротивлению уголковых н с док [4] по общепринятому ур внению для орош емых н с дочных конт ктных устройств [5]:

$$
\frac{\Delta P_{o p}}{h_{H c}}=\xi_{o p} \cdot W_{2}^{2} \cdot \frac{\rho_{2}}{\left(2 \cdot d_{9 K B}\right)}
$$

где $\frac{\Delta P_{o p}}{h_{\mu}}$ - гидр влическое сопротивление единицы высоты слоя орош емой н с дки,

/м; $\xi_{\text {op }}$ - коэффициент сопротивления орош емой н с дки; $W_{2}-$ действительн я

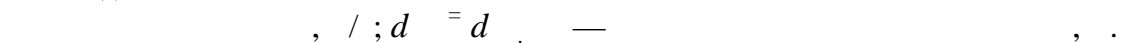

о эксперимент льным зн чениям $\left(\frac{\Delta P_{\mathrm{op}}}{h_{\text {нас }}}\right)$ эксл , полученным при р зличных $\mathrm{p}$ сход $\mathrm{x}$ г зовой ф зы (р зличных зн чениях $\left.w_{r}\right)$, p ссчитыв лись зн чения $\xi_{\text {ор }}$. езульт ты $\mathrm{p}$ счетов приведены в т блице и н рисунке в лог рифмических координ т х скоростного н пор г зовой фзы $\Delta P_{o p}-l g \xi_{\text {ор }}-l g R e_{\Gamma}$. бр ботк результ тов р счет по методу н именьших кв др тов позволил получить ур внения, удовлетворительно описыв ющие получившиеся з висимости:

) для уголковой н с дки

$$
\xi_{\text {op }}=354,8 \cdot \frac{10^{5}}{R e_{\Gamma}^{1,75}}
$$

б) для уголковой н с дки с верхней щелью

$$
\xi_{o p}=263,0 \cdot \frac{10^{4}}{\operatorname{Re}_{\Gamma}^{1,5}}
$$

в) для уголковой н с дки с отбойником пл вно изогнутой кромкой вниз

$$
\xi_{\text {op }}=185,0 \cdot \frac{10^{3}}{R e_{\Gamma}^{1,85}}
$$


езульт ты обр ботки эксперимент льных нных по гидр влическому сопротивлению уголковых н с док по ур внению(1)

\begin{tabular}{|c|c|c|c|c|c|c|c|c|c|}
\hline \multirow[b]{3}{*}{$\begin{array}{l}\text { 首 } \\
0\end{array}$} & \multirow{3}{*}{$\begin{array}{l}\sum_{\bar{\Sigma}}^{5} \\
>^{5} \\
m \\
\stackrel{5}{E} \\
0 \\
0 \\
0\end{array}$} & \multirow{3}{*}{ 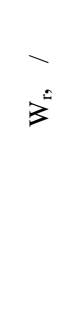 } & \multirow{3}{*}{ 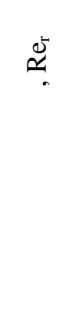 } & \multicolumn{6}{|c|}{ дельн я объемн я плотность орошения, м $^{3} /\left(\mathrm{M}^{2}\right.$ ч) } \\
\hline & & & & \multicolumn{2}{|c|}{8,5} & \multicolumn{2}{|c|}{18,2} & \multicolumn{2}{|c|}{29,1} \\
\hline & & & & 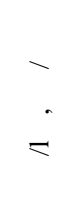 & 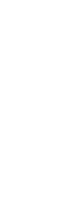 & 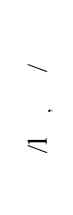 & 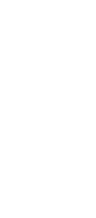 & 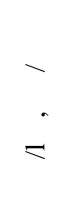 & 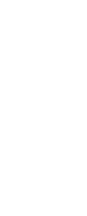 \\
\hline \multirow{4}{*}{ 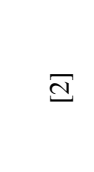 } & 1,28 & 0,046 & 92 & 396 & 9318 & 490 & 11529 & 517 & 12165 \\
\hline & 3,84 & 0,139 & 277 & 997 & 2570 & 902 & 2325 & 847 & 2183 \\
\hline & 9,76 & 0,352 & 703 & 1134 & 456 & 971 & 390 & 981 & 394 \\
\hline & 11,92 & 0,430 & 859 & 1347 & 363 & 1059 & 285 & 1043 & 283 \\
\hline \multirow{4}{*}{ 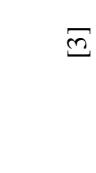 } & 3,84 & 0,102 & 156 & 343 & 1256 & 351 & 1286 & 311 & 1139 \\
\hline & 11,92 & 0,315 & 483 & 648 & 249 & 674 & 259 & 687 & 264 \\
\hline & 20,34 & 0,538 & 824 & 909 & 120 & 890 & 117 & 837 & 110 \\
\hline & 29,51 & 0,781 & 1195 & 1194 & 75 & 1086 & 68 & 1057 & 66 \\
\hline \multirow{4}{*}{$\begin{array}{l} \\
0 \\
0 \\
\text { 章 } \\
0 \\
0 \\
0 \\
0 \\
0\end{array}$} & 0,62 & 0,018 & 47 & 295 & 622 & 274 & 627 & 247 & 568 \\
\hline & 1,86 & 0,052 & 141 & 567 & 123 & 526 & 126 & 548 & 131 \\
\hline & 4,72 & 0,134 & 357 & 798 & 59 & 694 & 57 & 668 & 54 \\
\hline & 5,76 & 0,163 & 436 & 1050 & 36 & 847 & 33 & 845 & 34 \\
\hline
\end{tabular}

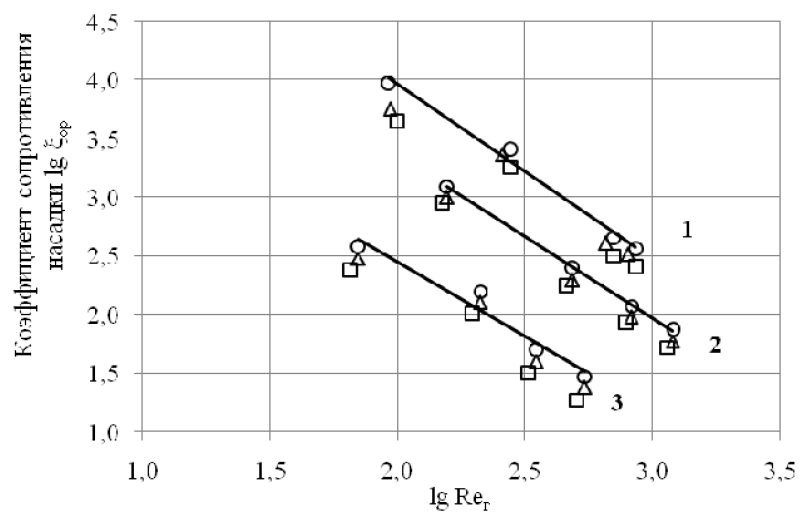

исунок. висимость коэффициент сопротивления уголковых н с докот режим течения г зовой ф зы при р зличной удельной плотности орошения:

1 -уголков ян с дк;2-уголков ян с дк сверхней щелью; 3 -уголков ян $c$ дк $c$ отбойником пл вно изогнутой кромкой вниз

помощью ур внения (2-4) для р счетного определения зн чений коэффициент сопротивления по эксперимент льным зн чениям Wг р ссчитыв лись зн чения $\left(\frac{\Delta \mathrm{P}_{\mathrm{op}}}{\mathrm{h}_{\text {нас }}}\right)_{\text {расчет }}$ и ср внив лись с соответствующими опытными зн чениями $\left(\frac{\Delta \mathrm{P}_{\mathrm{op}}}{\mathrm{h}_{\text {нас }}}\right)_{\text {эксп }}$.

роведенное ср внение пок з ло:

- н ибольшее отклонение р счетных зн чений гидр влического сопротивления исследуемых н с док от эксперимент льных д нных имеет место для уголковой н с дки при миним льном зн чении удельной плотности орошения $U=18,2 \mathrm{~m}^{3} /\left(\mathrm{м}^{2}\right.$ ч) средняя погрешность сост вляет $+25 \%$, что может быть объяснено неуст новившимся режимом течения жидкой ф зы по поверхности элементов н с дки; 
- при более высоких зн чениях удельной плотности орошения $U=18,2-29,1 \mathrm{~m}^{3} /\left(\mathrm{м}^{2}\right.$ ч) среднее отклонение р счетных зн чений гидр влического сопротивления уголковой н с дки с верхней щелью от эксперимент льных д нных во всем ди п зоне исследов нных н грузок по г зовой ф зе сост вляет +9 \%;

- $\quad$ отклонение р счетных зн чений гидр влического сопротивления уголковой н с дки с отбойником пл вно изогнутой кромкой вниз от эксперимент льных д нных в ди п зоне зн чений удельной плотности орошения $U=8,5-29,1 \mathrm{~m}^{3} /\left(\mathrm{м}^{2}\right.$ ч) и во всем ди п зоне исследов нных н грузок по г зовой ф зе сост вляет $+7 \%$.

ожно з ключить, что для р счет гидр влического сопротивления уголковых н с док в производственных условиях эксплу т ции может быть использов но ур внение (1). н чение коэффициент сопротивления для уголковой н с дки р ссчитыв ется по ур внению (2), для уголковой н с дки с верхней щелью - по ур внению (3), для уголковой н с дки с отбойником пл вно изогнутой кромкой вниз - по ур внению (4). огрешность р счетного определения зн чений $\left(\frac{\Delta P_{o p}}{h_{\text {нас }}}\right)$ не превыш ет $+7 \%$.

о результ т м исследов ния видно, что уголков я н с дк с отбойником пл вно изогнутой кромкой вниз имеет н именьший коэффициент сопротивления уголковых н с док от режим течения г зовой ф зы (см. рисунок).

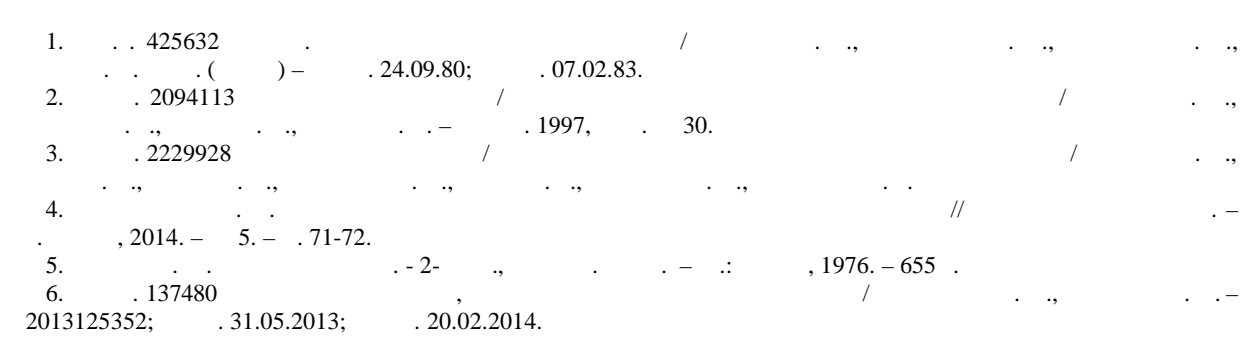

ведения об втор $x$

йруллин льмир нилович, спир нт, шкир ский госуд рственный университет, г. $\phi$, e-mail: almirmig@mail.ru

узнецов л димир лекс ндрович, д. т. н., профессор к федры « ехнологические м иины и оборудов ние», шкирский госуд рственный университет, 2. $\phi$, тел. $8(3472) 286210$
Information about the authors

Khairullin A. F., postgraduate of Bashkir State University,Ufa,e-mail: almirmig@mail.ru

Kuznetsov V. A., Doctor of Engineering, professor of the chair «Technological machines and equipment», Bashkir State University, Ufa, phone: 8(3472)286210 